\section{Cardiac protection by preoperative intervention in noncardiac surgery}

HELFRIED METZLER • S. ARCHAN
HELFRIED METZLER ( $\square$ )

Professor and Chairman Department of Anesthesiology and Intensive Care Medicine

Medical University of Graz

Auenbruggerplatz 29

A-8036 Graz, Austria

Phone: ++433163854663

Fax: $\quad++433163854664$

e-mail: helfried.metzler@meduni-graz.at

S. ARCHAN

Resident

\begin{abstract}
Preoperative coronary intervention is one option to optimize the cardiac risk patient scheduled for noncardiac surgery. Such an intervention, however, is only justified for high risk procedures and if the indication for preoperative intervention is independent from surgery.

Currently, PTCA with stent implantation is the most commonly used practice. Dependent of the type of stent (bare-metal stent or drug-eluting stent) dual antiplatelet therapy is mandatory for 1 - 12 months.

The surgeon, the cardiologist and the anesthesiologist have to decide in an interdisciplinary approach the perioperative management to navigate the patient between stent thrombosis and surgical bleeding.
\end{abstract}

Key words: noncardiac surgery, cardiac risk, percutaneous coronary intervention, coronary stents

Coronary intervention may be one effective strategy to optimize the cardiac risk patient scheduled for noncardiac surgery (fig. 1). Available studies confirm a benefit of such an intervention if the indications for preoperative testing and intervention are independent from the surgical procedure (1, 2, 3). A net benefit of a preoperative intervention only exists if morbidity/mortality of noncardiac surgery without any pre-operative intervention (= immediate clearance for surgery) is $\geq$ morbidity/mortality of noncardiac surgery after extensive testing and intervention (fig. 2). Patients with low and intermediate risk procedures will not benefit.

Outcome of patients after prophylactic revascularization before noncardiac surgery seems not be different from patients with conservative management $(4,5)$.
There has been a dramatic change in the landscape of coronary intervention in the last decade. Percutaneous coronary intervention dominates over coronary artery bypass graft surgery, and PTCA with coronary artery stenting is the preferred interventional strategy. Therefore, anesthesiologists are more

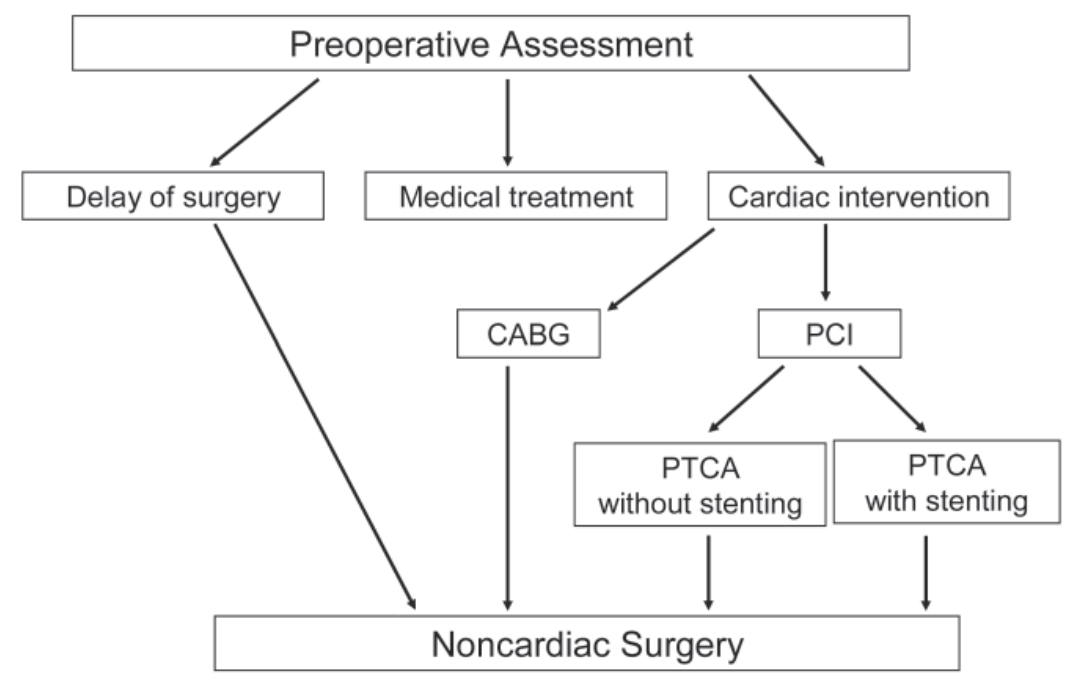

Figure 1

Preoperative optimization of the coronary risk patient scheduled for noncardiac surgery 


\section{$M M_{a}>\quad M M_{b+c+d+e}$}

MM Morbidity and mortality resulting from

a Non-cardiac surgery without intervention

b Pre-operative extensive testing

c Pre-operative revascularization procedure

d Delay of non-cardiac surgery

e Non-cardiac surgery after intervention

Figure 2

A net benefit of preoperative testing and intervention only exists if $M / M a>M / M b+c+d+e$ and more confronted with patients after recent coronary artery stenting scheduled for noncardiac surgery. Coronary artery stenting implicates the need for dual antiplatelet drug therapy, usually with clopidogrel and aspirin. Discontinuation of dual antiplatelet drug therapy increases the risk of perioperative stent thrombosis and continuation of the risk of surgical bleeding.

Kaluza et al reported an alarming 20\% perioperative mortality rate (6).

In 2003 Wilson et al published a retrospective study of 207 patients. 4\% of them suffered from cardiac events inclusive of 6 patients, who died (7).

Recently, Vicenzi et al published a prospective outcome study enrolling all patients with a coronary artery stent within one year before NCS. $44 \%$ suffered from complications after surgery, $4.9 \%$ died (8, fig. 3). All, but two (bleeding only) adverse events were of cardiac nature. The risk of suffering an event was 2.11 fold greater in patients with recent stents $(<35$ days before surgery) as compared with $\mathrm{PCl}$ more than 90 days before surgery.

In the nonsurgical setting cardiologic trials documented greater bleeding risk when clopidogrel and aspirin were combined, compared to aspirin alone
(9). Most of the surgical data comes from clinical studies in patients undergoing CABG-surgery $(10,11)$. Clopidogrel, a thienopyridin, inhibitsplateletaggregation by irreversible blockade of adenosin diphosphat mediated platelet function. Normalization depends on the new platelet population. Most CABG-studies demonstrated that clopidogrel given within 4 to 5 days before CABG-surgery increased transfusion requirements and prolonged ICU-stay $(10,11)$.

\section{Recommended dual antiplatelet drug regime after stent implantation} concluded that there is uncertainty regarding how much time should pass between $\mathrm{PCl}$ and NCS procedures. If a coronary stent is used, a delay of at least two weeks and ideally 4 to 6 weeks should occur before NCS to allow 4 full weeks of dual antiplatelet therapy and reendothelialization of the stent to be completed or nearly so (12).

The new Guidelines of the European Society of Cardiology for percutaneous coronary artery intervention recommend that after implantation of a bare metal stent clopidogrel must be continued for 3 to 4 weeks and ASA lifelong, after drugeluting stents clopidogreland ASA should be administered for 6 to 12 months to avoid late vessel thrombosis (13).

The new ACC/AHA 2005 Guideline update for percutaneous coronary intervention recommends that in patients who have undergone $\mathrm{PCl}$, clopidogrel $75 \mathrm{mg}$ daily should be given for at least 1 month after bare-metal stent implantation (unless the patient is at an increased risk for bleeding; then it should be given for a minimum of 2 weeks), 3 months after sirolimus stent implantation, and 6 months after paclitaxel stent implantation, and
The ACC/AHA Guidelines from 2002

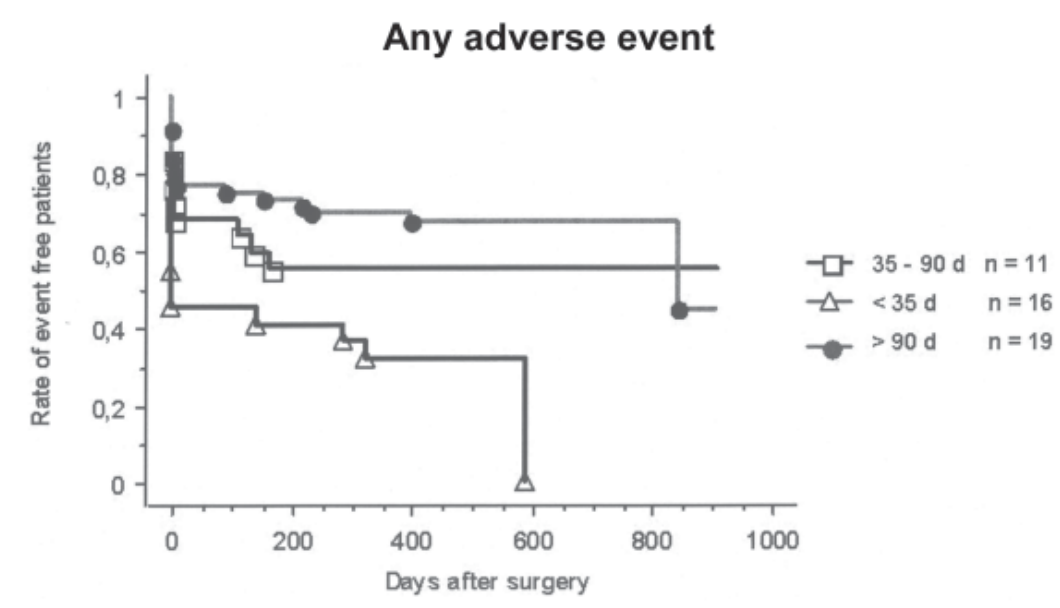

Figure 3

Kaplan-Meier event time curve (combined coronary and bleeding events) of 103 patients receiving a coronary artery stent within 1 year before noncardiac surgery (8). 
ideally up to 12 months in patients who are not at high risk of bleeding (level of evidence B) (14).

\section{Perioperative management}

Currently, many case reports and retrospective studies are available but no large prospective randomized trials. Therefore, we have to rely on recommendations of task forces and expert opinions (12-14).

Basically, when assessing the perioperative risk of patients with recent coronary artery stenting before noncardiac surgery we have to plot the risk of thrombosis vs. the risk of bleeding (fig. 4). Dual antiplatelet regime can be stopped, changed or continued according to this assessment. Figure 4 shows the algorithm for preoperative management according to the urgency of noncardiac surgical procedures. Depending on the calculation of the thrombosis/bleeding risk 3 options are possible:

1. Continue clopidogrel + aspirin e.g. peripheral vascular surgery can be performed under dual antiplatelet drug regime because vascular surgeons are familiar with such situations.

2. Continue aspirin, stop clopidogrel This concept balances in many cases the risk benefit ratio

3. Stop clopidogrel, stop aspirin
This option should be strictly restricted to high bleeding procedures, like urologic, intracranial and some types or tumor surgery.

Essentially, patients with recent coronary artery stents and dual antiplatelet therapy scheduled for noncardiac surgery benefit from a close collaboration between the surgeon, the anesthesiologist and the cardiologist.

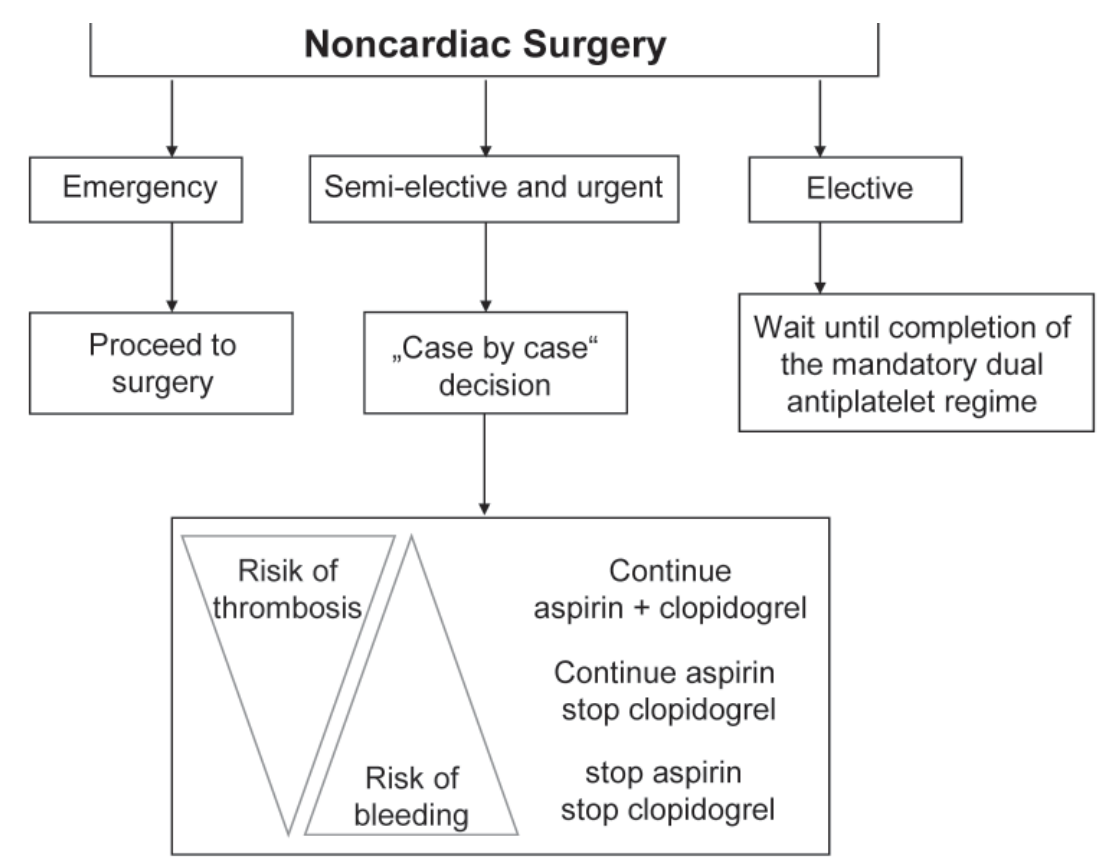

Figure 4

Algorithm for preoperative management of patients after $\mathrm{PCI}$ with dual antiplatelet drug therapy.

\section{REFERENCES}

1. Eagle KA. Cardiac risk of noncardiac surgery. Influence of coronary disease and type of surgery in 3368 patients. Circulation 1997;96:1882-7.

2. Fleisher LA, Eagle KA, Shaffer T, Anderson GF. Perioperative and longterm mortality rates after major vascular surgery: The relationship to preoperative testing in the medicare population. Anesthesia Analgesia 1999;89:849-55.

3. Fleisher LA, Eagle KA. Lowering cardiac risk in noncardiac surgery. New England Journal of Medicine 2001;345:1677-82.

4. McFalls E, Ward HB, Moritz TE, Goldman S, Krupski WC, Littooy F, Pierpont G, Santilli S, Rapp J, Hattler B, Shunk K, Jaenicke C, Thottapurathu L, Ellis N, Reda DJ, Henderson WG. Coronary-artery revascularization before elective major vascular surgey. New England Journal of Medicine 2004;351:2795-804.

5. Godet G, Riou B, Bertrand M, Fléron HH, Goarin JP, Montalescot G, Coriat P. Does preoperative coronary angioplasty improve perioperative cardiac outcome? Anesthesiology 2005;102:739-46.

6. Kaluza GL, Joseph J, Lee JR, Raizner ME, Raizner AE. Catastrophic outcomes on noncardiac surgery soon after coronary stenting. Journla of the American College of Cardiology 2000;35:1288-94.

7. Wilson SH, Fasseas P, Orford JL, Lennon RJ, Horlocker T, Charnoff NE, MelbyS, Berger PB. Clinical outcome of patients undergoing noncardiac surgery in the two months following coronary stenting. Journal of the Amercian College of Cardiology 2003;42:234-50.

8. Vicenzi MN, Meislitzer T, Heitzinger B, Halaj M, Fleisher LA, Metzler H. Coronary artery stenting and non-cardiac surgery - a prospective outcome study. British Journal of Anaesthesia 2006;96:686-93.

9. Yusuf S, Zhao F, Mehta SR, Chrolavicius S, Tognnoni G, Fox KK. Effects of clopidogrel in addition to aspirin in patients with acute coronary syndromes without ST-segment elevation. New England Journal of Medicine 2001;345:494-502. 
10. Chu MWA, Wilson SR, Novick RJ, Stitt LW, Quantz MA. Does clopidogrel increase blood loss following coronary artery bypass surgery? Annals of Thoracic Surgery 2004;78:1536-41.

11. Ascione R, Ghosh A, Rogers CA, Cohen A, Monk C, Angelini GD. In-hospital patients exposed to clopidogrel before coronary artery bypass graft surgery: A word of caution. Annals of Thoracic Surgery 2005;79:1210-6.

12. ACC/AHA Practice Guidelines. ACC/AHA guideline update for perioperative cardiovascular elevation for noncardiac surgery - executive summary. Journal of the American College of Cardiology 2002;39:542-53.

13. ESC Guidelines for Percutaneous Coronary Interventions. The task force for percutaneous coronary interventions of the European Society of Cardiology. Guidelines for percutaneous coronary interventions. European Heart Journal 2005;26:804-47.

14. ACC/AHA/SCAI. Guideline update for percutaneous coronary intervention - summary article: a report of the American College of Cardiology/American Heart Association Task Force on practice guidelines. Journal of the American College of Cardiology 2006;47:216-35 